\title{
Influences of Different Die Bearing Geometries on the Wire-Drawing Process
}

\author{
Gustavo Aristides Santana Martinez ${ }^{1, *}$, Eduardo Ferro dos Santos ${ }^{1}{ }^{\mathbb{D}}$, \\ Leonardo Kyo Kabayama ${ }^{2} \mathbb{D}$, Erick Siqueira Guidi ${ }^{3} \mathbb{D}$ and Fernando de Azevedo Silva ${ }^{3}$ \\ 1 Engineering School of Lorena, University of São Paulo-USP, Lorena 12602-810, Brazil; Eduardo.ferro@usp.br \\ 2 Institute of Mechanical Engineering, Federal University of Itajubá-UNIFEI, Itajubá 37500-903, Brazil; \\ lkabayama@unifei.edu.br \\ 3 Guaratinguetá School of Engineering, Campus de Guaratinguetá, São Paulo State University-UNESP, \\ 12516-410 Guaratinguetá, Brazil; Erick.s.guidi@unesp.br (E.S.G.); fernando.azevedo@unesp.br (F.d.A.S.) \\ * Correspondence: gustavo.martinez@usp.br; Tel.: +55-12-3159-5337
}

Received: 2 September 2019; Accepted: 8 October 2019; Published: 10 October 2019

\begin{abstract}
Metalworking is an essential process for the manufacture of machinery and equipment components. The design of the die geometry is an essential aspect of metalworking, and directly affects the resultant product's quality and cost. As a matter of fact, a comprehensive understanding of the die bearing geometry plays a vital role in the die design process. For the specific case of wire drawing, however, few efforts have been dedicated to the study of the geometry of the bearing zone. In this regard, the present paper involves an attempt to investigate the effects of different geometries of the die bearing. For different forms of reduction as well as bearing zones, measurements are carried out for the wire-drawing process. Subsequently, by extracting the friction coefficients from the electrolytic tough pitch copper wire in cold-drawn essays, the numerical simulations are also implemented. We present the results on both the superficial and center radial tensions obtained by finite element methods. It is observed that the reduction of the friction coefficient leads to an increase in radial stress, while for a given friction coefficient, the substitution of the C-type die by the R-type one results in a decrease in the superficial radial stress of up to $93.27 \%$, but an increase at the center of the material. Moreover, the die angle is found to play a less significant role in the resultant center radial stress, but it significantly affects the superficial radial stress. Lastly, R-type dies result in smaller superficial radial stress, with a change of up to $34.48 \%$, but a slightly larger center radial stress up to $6.55 \%$ for different die angles. The implications of the present findings are discussed.
\end{abstract}

Keywords: wire drawing; finite element method; drawing die; die geometry; radial stress; friction

\section{Introduction}

The influence of die drawing in the metalworking processes has attracted much attention. A vital feature of the process is that the resulting stress is applied indirectly by an external source, as in the cases of extrusion [1,2] and wire drawing [3]. Previous studies on wire drawing have reported the improvement of the drawing quality by selecting the appropriate die geometry (Figure 1). The influence of the reduction zone as well as the bearing zone is known to significantly affect the drawing force, spatial profile of the radial stress, residual stress behavior, and properties of the resultant wire [4-12]. 


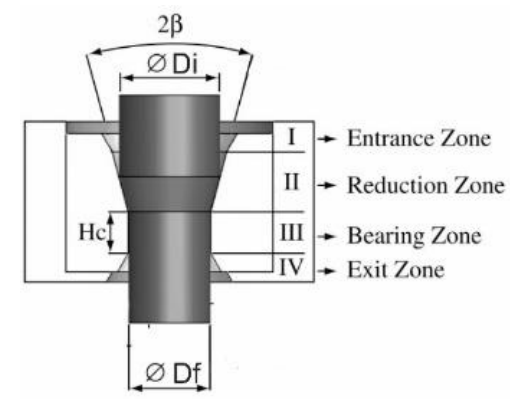

Figure 1. Schematic illustration of the internal longitudinal section structure of the wire die.

Variations in radial stress affect the mechanical properties, and subsequently, the quality of the drawn product, which might lead to disqualification. Such defects include shape distortion, crack propagation, inferior surface finish quality, and reduced dimensional accuracy [13-17]. For instance, it has been demonstrated in $[18,19]$ that the radial stress due to specific die bearing contour geometry has a significant impact on the degree of residual stress.

A reduction zone determines the primary deformation during the plastic metal forming process, indicated by the $\Delta$ parameter defined in Equations (1) and (2). To be more specific, it gives the relationship between the geometrical measures and the semi die angle $\beta$, which consequently affects the drawing force and friction [20-22].

$$
\begin{gathered}
\Delta=\frac{\beta}{\mathrm{r}_{\mathrm{a}}}\left[1+\sqrt{1-\mathrm{r}_{\mathrm{a}}}\right]^{2} \\
\mathrm{r}_{\mathrm{a}}=1-\frac{\mathrm{A}_{\mathrm{f}}}{\mathrm{A}_{\mathrm{i}}},
\end{gathered}
$$

where $r_{a}$ is the reduction in area and $\beta$ is the semi-angle of the die in radians.

In [7], Kraft et al. reported the process of drawing a commercial electrolytic tough pitch copper (Cu-ETP) wire in an annealed condition at low speed with a drawing block. The authors showed that different die angles result in significant differences in the parameter $\Delta$, strain rate, and total deformation strain (due to redundant strain). Atkins [22] observed that the deformations in the cases $\Delta \geq 1$ can be better explained by the redundant work factor $(\Phi)$. The factor $\Phi$ is defined by the ratio of the total deformation work to that due to dimension change. In other words, it carries the information on the additional plastic deformation besides those owing to the cross-sectional area reduction. The corresponding value for $\mathrm{Cu}$-ETP is found to be

$$
\Phi \approx 1+0.27 \Delta .
$$

Other studies by Nakagiri [8], Coser [17], and Godfrey [23] focused on the effects of the wire/die contact length to diameter ratio $(\mathrm{L} / \mathrm{Di})$. Here the length of $\mathrm{L}$ is defined as the sum of the frustum slant length at $2 \beta$ die angle and the length of the bearing zone Hc indicated in Figure 1. It was shown that both the L/Di ratio and residual stress were small.

Nonetheless, for the specific case of wire drawing die, to the best of our knowledge, few efforts have been dedicated to the geometry of the bearing zone. Therefore, the main object of the present paper is to evaluate the effects of die contours. To be specific, we study different forms of die geometry and its impact on reducing the radial stress during and after the wire-drawing process. Therefore, the present study will potentially improve the organizational process in terms of the reduction of shape distortion, crack propagation, surface finish quality, and dimensional accuracy of the parts.

\section{Materials and Methods}

A better understanding of the effects of the die geometry in the process of plastic deformation provides valuable information and potential for further development in practice. In the present study, 
we focus on the influences of the reduction and bearing zones of the wire drawing die. The work is divided into three stages. In the first part of the study, tensile testing in commercial Cu-ETP $(99.94 \%$ $\mathrm{Cu}$ ) with $\varnothing 0.5 \mathrm{~mm}$ and a length of $200 \mathrm{~mm}$ in the annealed condition was performed using a tensile test machine. The object was to obtain the mechanical properties of specimens. The experimental data collected from the wire-drawing process at different speeds were used to calculate the friction coefficient $(\mu)$. At this stage, cold wire drawing with a single block drawing was used. The first type of die was made of crystal poly diamond (PCD) with $2 \beta=10^{\circ}$ and $\mathrm{Hc}=35 \% \mathrm{Df}$, which will be denoted as C-type. Here, water-soluble oil and mineral lubricants were implemented. The drawing stress was determined by measuring the drawing load using a load cell system mounted on the die. The object of the second stage was to simulate the process by employing a finite-element solver. Calculations were carried out for the radial stress both at the center and on the surface of the material. For the purposes of comparison, four different values of $\mu$ were selected, obtained from the first stage, to perform the numerical simulations. Besides the C-type dies, a different type of drawing die was introduced, whereby the straight cylindrical bearing zone of length $\mathrm{Hc}$ is substituted by an inwardly curved bearing zone with (contour) length $\mathrm{R}$, which will be referred to as an R-type die hereafter.

The Ansys workbench 15, a finite element program based on quasi-static formulation, is employed for the numerical simulations. Due to the existing symmetry presented in the problem, only one-quarter of the real die geometry is implemented numerically in the three-dimensional model (Figure 2). In practice, we consider the die as a rigid body, whereas the behavior of the material is modeled by a multilinear isotropic hardening curve. To generate the finite element meshes, elements such as SOLID186, MASS21, TARGE170, and CONTA174 are made use of. The real contact between the die and the thread is the frictional type, namely, solid to solid friction is implemented by using different values for the friction coefficient, as discussed above. Moreover, adaptive mesh refinement is carried out regarding the accuracy of the calculations. The process is invoked until the variations of the surface and center radial stresses become less than $10 \%$ with respect to the latest one. By using the static implicit method, the resultant mesh contains, on average, 23,000 nodes and 5000 elements. Also, substeps have been utilized to accelerate the convergence, as well as to facilitate the subsequent interpolation for spatial profiles of the stress. The size of substep varies from 0.005 to $0.02 \mathrm{~s}$, while the total increment of one step is $1 \mathrm{~s}$. For the third and last stage, additional simulations are carried out with the aim of analyzing the radial stress resulting from the C-type and R-type dies. It is done by choosing different die angles $2 \beta$ with 14 and 18 degrees, together with the smallest $\mu$ that occurs in the experimental wire-drawing process at different speeds. Last but not least, in order to validate the finite element model, the resultant drawing forces extracted from the numerical simulations are compared against those obtained empirically, as shown below in Figure 4. The discrepancies between the experimental and theoretical ones are found to be around $10 \%$. These are attributed, by and large, to the differences in the model implementations regarding the specific type of lubricant used in practice as well as other uncertainty, presented experimentally. We understand, therefore, that our present finite element approach is reasonable, and the main features derived from the numerical simulations are meaningful.

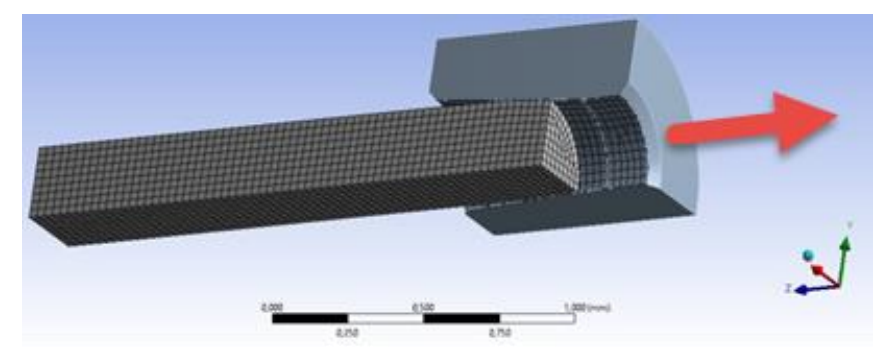

Figure 2. An illustration of the geometrical layout and the mesh of finite elements used in numerical simulations. The red arrow indicates the drawing direction. 


\section{Results}

As discussed before, we first determine the mechanical properties by carrying out a tension test of the samples used in the wire drawing process, which will be utilized later for numerical simulations. The relevant measurements include elastic modulus $(\mathrm{E}=14 \mathrm{GPa})$, yield strength $\left(\sigma_{\mathrm{e}, 0.2 \%}=130 \mathrm{MPa}\right)$, tensile stress limit $\left(\sigma_{\mathbf{r}}=349 \mathrm{MPa}\right)$, and Poisson's ratio (0.34). In Figure 3 we show the experimental results of Cu-ETP wire drawing of $\varnothing 0.5$ (Di) to $\varnothing 0.45 \mathrm{~mm}$ (Df), performed with C-type die with $2 \beta=10^{\circ}$ and $\mathrm{Hc}=35 \%$ Df. The total strain in one pass was $19 \%$ (ra) for varied speeds from 0 to $25 \mathrm{~m} / \mathrm{s}$. The increase in speed causes a specific variation in the drawing force for each type of lubricant, as shown in Figure 3. This is understood to be due to the lubricant listed in Table 1 and its ease of entering the metal/die interface. It was not possible to measure the dynamic viscosity of the water-soluble lubricant, which contains $93 \%$ water in its composition.

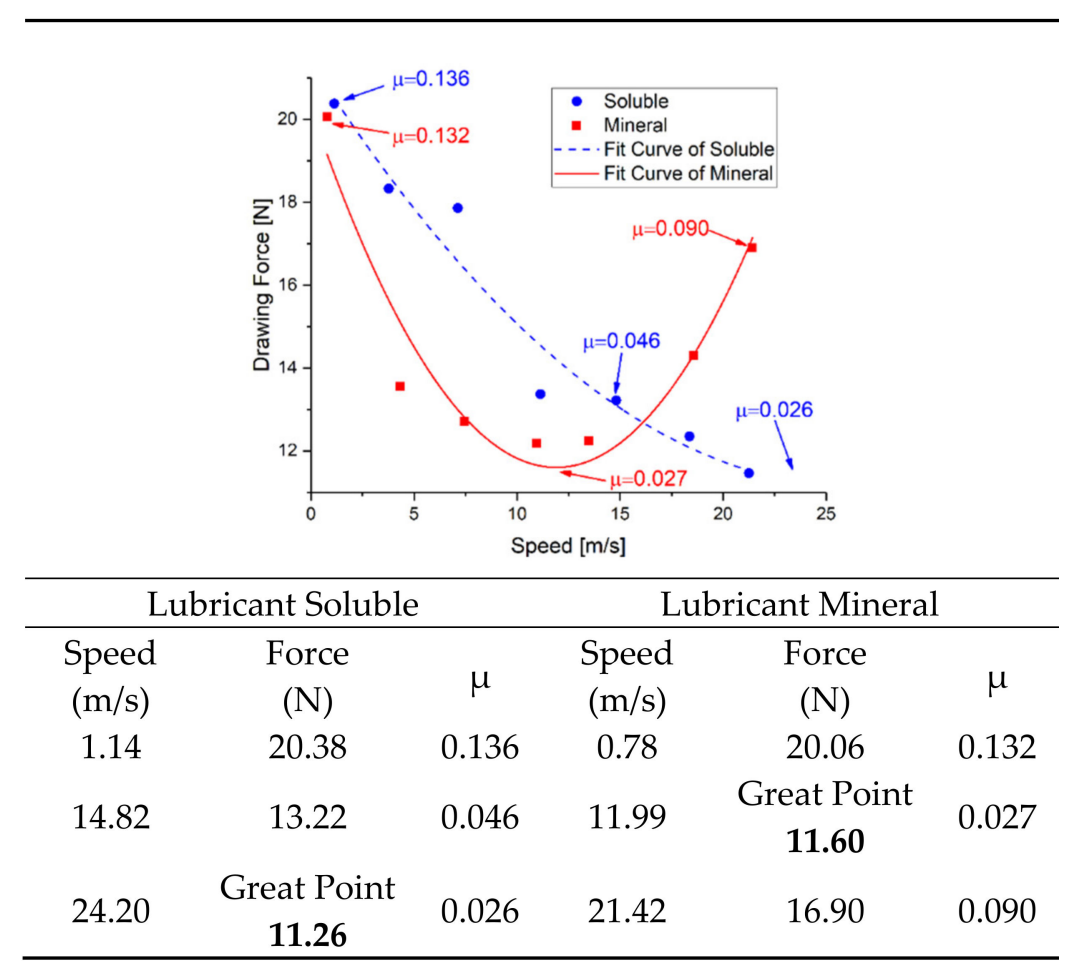

Figure 3. Experimental results obtained in C-type copper wire drawing process with mineral and soluble lubricants for different speeds.

Table 1. Dynamic viscosity at different temperatures.

\begin{tabular}{ccc}
\hline Temp. $\left({ }^{\circ} \mathrm{C}\right)$ & \multicolumn{2}{c}{ Viscosity (Pa.s) } \\
\cline { 2 - 3 } & Soluble & Mineral \\
\hline 25 & Out of range & 0.2940 \\
50 & & 0.0704 \\
70 & & 0.0448 \\
\hline
\end{tabular}

By using the mineral lubricant, the drawing force is found to attain the minimum value $(11.60 \mathrm{~N})$ at a relatively low speed $(11.99 \mathrm{~m} / \mathrm{s})$ compared to that for the soluble lubricant $(24.20 \mathrm{~m} / \mathrm{s})$ due to its larger viscosity. On the other hand, an increase in the drawing force is observed for the former as the speed exceeds $11.99 \mathrm{~m} / \mathrm{s}$. This probably occurs owing to the excess of lubricant in the metal/die interface. The results indicate that the optimized conditions of the process, namely, the lowest drawing force, are presented at different speeds, depending on the specific type of lubricant.

The second stage starts with the calculation of friction coefficients, determined by the experimental data on drawing force at different speeds, whereby Equations (4) and (5) were derived [24]. 
The corresponding results are presented in Figure 3. The results show that the smallest $\mu(0.026)$ occurs in the drawing with water-soluble oil at a drawing speed of $24.20 \mathrm{~m} / \mathrm{s}$. The specific values of the friction coefficient employed in the simulations (Figure 3) with Ansys-15 are 0.136 (soluble), 0.046 (soluble), 0.090 (mineral), and 0.026 (soluble), respectively, in accordance with standard practice.

$$
\begin{array}{r}
\mu=\frac{\sigma_{0} \cdot\left(\frac{\sigma_{x b}}{\sigma_{0}}+2 \cdot f(\beta) \cdot \ln \frac{r_{i}}{r_{f}}+\frac{2}{\sqrt{3}} \cdot\left(\frac{\beta}{\sin ^{2} \beta}-\cot g \beta\right)\right)-\sigma_{x f}}{2 \cdot\left(\left(\frac{H c}{r_{f}} \cdot \sigma_{x f}\right)-\left\{\sigma_{0} \cdot\left[(\cot g \beta) \cdot\left(1-\frac{\sigma_{x b}}{\sigma_{0}}-\ln \frac{r_{i}}{r_{f}}\right) \cdot \ln \frac{r_{i}}{r_{f}}+\frac{H c}{r_{f}}\right]\right\}\right)} \\
f(\beta)=\frac{\left\{1-(\cos \beta) \cdot \sqrt{1-\frac{11}{12} \cdot \sin ^{2} \beta}+\frac{1}{\sqrt{11 \cdot 12}} \cdot \ln \frac{1+\sqrt{\frac{11}{12}}}{\sqrt{\frac{11}{12}} \cdot \cos \beta+\sqrt{1-\frac{11}{12} \sin ^{2} \beta}}\right\}}{\operatorname{sen}^{2} \beta},
\end{array}
$$

where $\sigma_{0}$ stands for the yield stress, $\sigma_{\mathrm{xb}}$ is the backward stress, and $\sigma_{\mathrm{xf}}$ is the wire-drawing stress, while $r_{i}$ and $r_{f}$ indicate the initial and final radii of the wire, respectively.

In order to study the effect of the internal die geometry, both the C-type die with a cylindrical bearing zone of length $\mathrm{Hc}$ and the R-type die with the radius $\mathrm{R}$ at its narrowest region are utilized. To be specific, the following measures are utilized for the C-type $\left(2 \beta=10^{\circ} ; \mathrm{Hc}=35 \% \mathrm{Df}\right)$ and R-type $\operatorname{dies}\left(2 \beta=10^{\circ} ; \mathrm{R}=1,2 \mathrm{~mm}\right)$. The values of the radius $\mathrm{R}$ of $\mathrm{R}$-type dies are chosen in such a way to maintain the contact length $\mathrm{L}$, identical to that of the C-type dies. The purpose of the above setup is that the ratio L/Di should not influence the stress [8]. The values of $\mathrm{L}$ shown in Table 2 are evaluated by the sum of the contact length, namely, the sum of the length of reduction zone and Hc (R) for C-type (R-type) dies.

\begin{tabular}{|c|c|c|c|c|c|c|}
\hline \multicolumn{3}{|c|}{ C-Type } & \multicolumn{4}{|c|}{ R-Type } \\
\hline & 0,19 & $\underbrace{10}_{\text {eitent }}$ & & 0.19 & acement ${ }^{\text {st }}$ & \\
\hline \multirow{2}{*}{ L/Di. } & \multirow{2}{*}{$\underset{(\mathrm{mm})}{\mathrm{L}}$} & \multirow{2}{*}{$\begin{array}{l}\text { Hc } \\
(\%)\end{array}$} & \multirow{2}{*}{$\begin{array}{l}2 \beta \\
\left(^{\circ}\right)\end{array}$} & $\mathrm{R}$ & $\mathrm{L}$ & \multirow{2}{*}{$\mathrm{L} / \mathrm{Di}$} \\
\hline & & & & \multicolumn{2}{|c|}{$(\mathrm{mm})$} & \\
\hline 0.889 & 0.4443 & 35 & \multirow{2}{*}{10} & \multirow[t]{2}{*}{1.0} & 0.4443 & 0.889 \\
\hline- & - & - & & & 0.4442 & 0.888 \\
\hline 0.726 & 0.3631 & \multirow{2}{*}{35} & 14 & \multirow[t]{2}{*}{2.0} & 0.3629 & 0.726 \\
\hline 0.636 & 0.3182 & & 18 & & 0.3176 & 0.635 \\
\hline
\end{tabular}

Table 2. Dimension of die geometry used in numerical simulation.

The values of the radial stresses are extracted from the simulations both at the center and the surface of the materials. In particular, as indicated in Table 2, a point on the surface and another at the center of the material are chosen to be monitored due to their distinctive roles during the wire-drawing process. The stress on the surface of the material is primarily applied by the die, and the stress at the center of the material is mostly identical to the external force exerted by the capstan.

In Figure 4, we present the results on radial stress as a function of displacement. It can be inferred that the reduction of fraction coefficient $\mu$ implies an increase in the radial stress, both on the surface and at the center of the material for both types of dies (C-type and R-type). Moreover, for a given $\mu$, the R-type dies result in less radial stress on the surface than do C-type dies. On the other hand, the radial stress is observed to increase in the center of the material. This happens due to the decrease of redundant work and, consequently, the increase of the material flow. As a result, the radial stress between the center and surface becomes closer, which in turn increases the homogeneity in plastic 
deformation. The above feature is observed to be more prominent as the value of $\mathrm{R}$ increases from $\mathrm{R}=1 \mathrm{~mm}$ to $\mathrm{R}=2 \mathrm{~mm}$. These results are in accordance with Vega's findings [25]. In other words, the bearing length has a significant impact on the drawing process of copper.

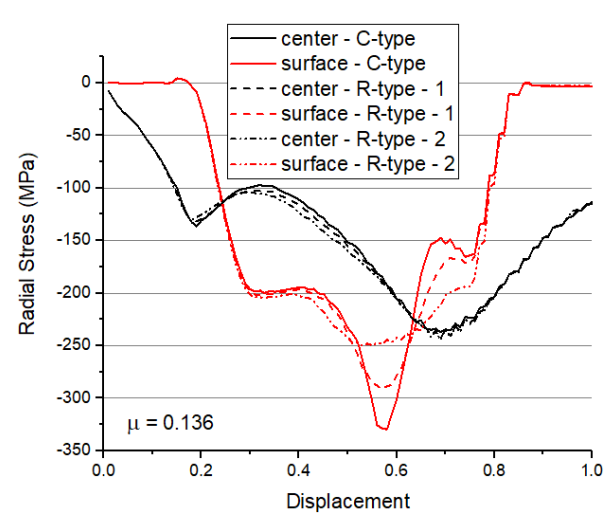

(a) $\mu=0.136$

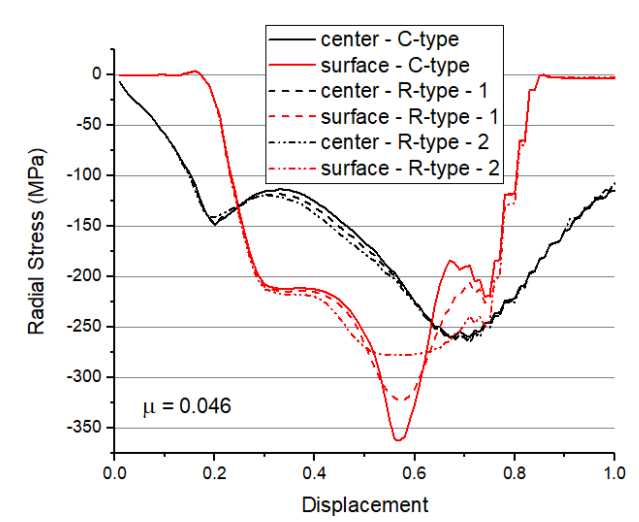

(c) $\mu=0.046$

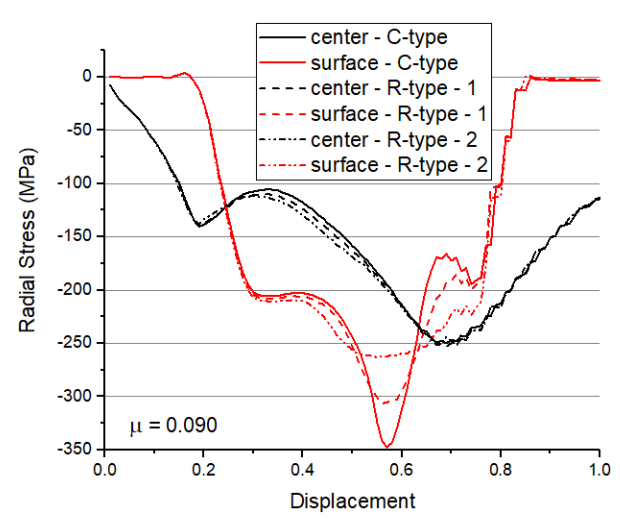

(b) $\mu=0.090$

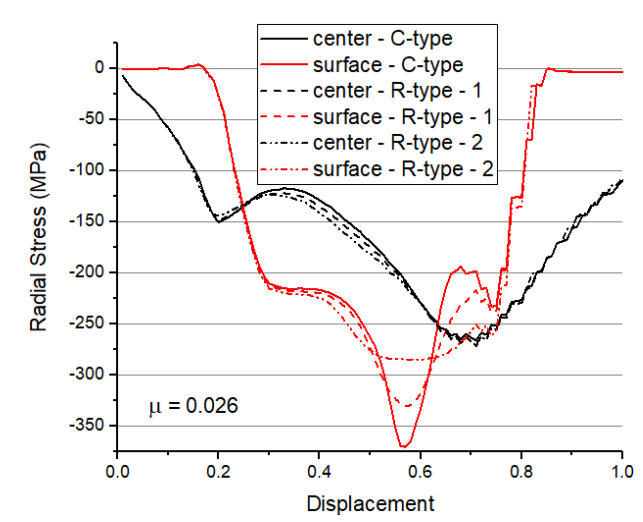

(d) $\mu=0.026$

Figure 4. The calculated radial stress as a function of displacement, obtained by the finite element methods with different coefficients of friction.

For the third and last stage, different die angles $(2 \beta)$ together with given $\mu=0.026$ are utilized in numerical simulations in order to investigate the effect of the reduction region on radial stress. We choose two angles with $2 \beta=14^{\circ}$ and $18^{\circ}$, which are commonly adopted in industry practice. Also, $\mathrm{R}=2 \mathrm{~mm}$ is chosen to reduce the surface as well as the center radial stress and, consequently, to increase the homogeneity in the plastic deformation of the material. The numerical results are presented in Figure 5. For a clear understanding of the different regions of the drawing die in question, we have chosen three evaluation points with different displacements, namely 0.4 (start of the deformation zone), 0.6 (start of bearing zone), and 0.8 (final region of the die), as indicated in Figure 5 a. The values of radial stress of the mentioned points were evaluated and presented in Figure $5 \mathrm{~b}$ for the center radial stress and Figure $5 \mathrm{c}$ for the superficial radial stress. 


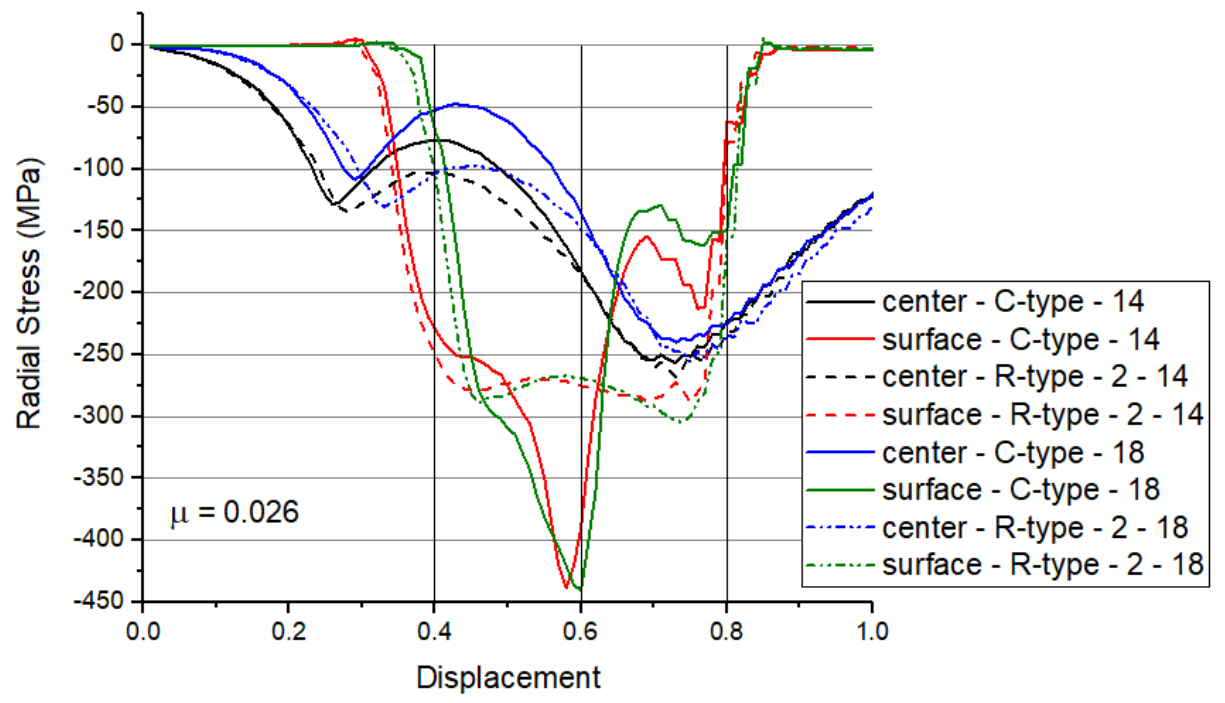

(a) Evaluation Points

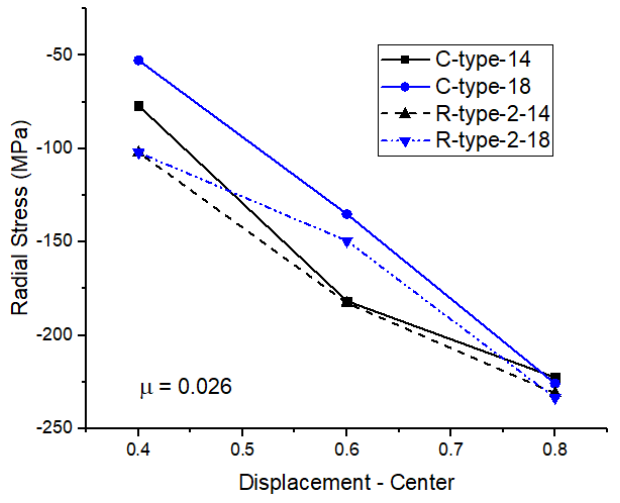

(b) Center

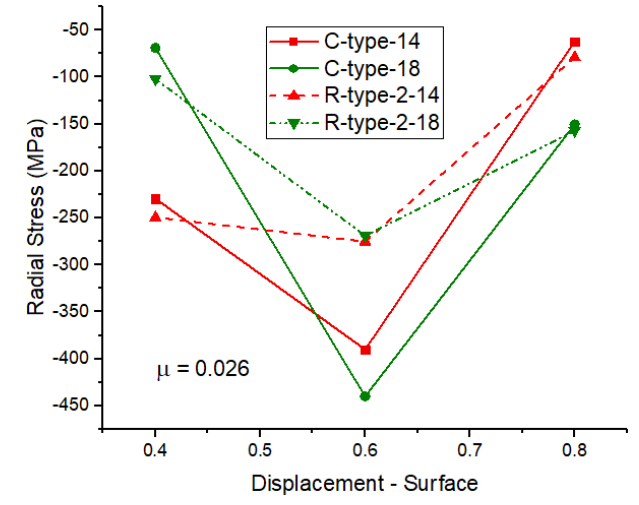

(c) Surface

Figure 5. (a) Evaluation points. (b) The center radial stress as a function of displacement, evaluated for the evaluation points. (c) The superficial radial stress as a function of displacement, evaluated for the evaluation points.

For a given friction coefficient $\mu=0.026$, the variation of the die angle $2 \beta$ has a less significant impact on the radial stress in the center of the material, compared to that on the surface of the material, as shown in Figure 5b,c. Subsequently, as the redundant work decreases, it enables one to increase the material flow, which is accompanied by a slight increase in the radial stress at the center of the material. This result can be intuitively understood as the surface of the material that suffers heavily from the deformation process. The observed variation in radial stress takes place as a reaction to the increase in the parameter $\Delta$ and the subsequent impact on the redundant work factor $\Phi$, as shown in Table 3 .

Table 3. The calculated redundant work factor $\Phi$ as a function of $\Delta$ and $2 \beta$ used in numerical simulations.

\begin{tabular}{ccc}
\hline $\mathbf{2} \boldsymbol{\beta}$ & $\boldsymbol{\Delta}$ & $\boldsymbol{\Phi}$ \\
\hline 14 & 2.32 & 1.62 \\
18 & 2.98 & 1.8 \\
\hline
\end{tabular}

On the other hand, the superficial radial stress is significantly influenced by the increase of the die angle $2 \beta$. Consequently, the most substantial flow of material also occurs for the die angle of $2 \beta$ $=14^{\circ}$. At the entrance region (point 0.4 ) the superficial radial stress is slightly more significant for 
the die angle $2 \beta=14^{\circ}$, as shown in Figure $5 \mathrm{c}$. The central region (point 0.6 ) clearly demonstrates the most substantial influence between different types of dies. The radial stress in the final region of the die (point 0.8 ) is influenced by a flow facility permitted by the smaller angle of $2 \beta$. With the aim of comparing the behaviors of different types of dies, the higher radial stresses at the center and on the surface of the material are chosen and presented in Figure 6. From Figure 6, it can be inferred that the modification of the die geometry from C-type to R-type reduces the radial stress on the surface of the material (between $-23.10 \%$ and $-34.48 \%$ ) but increases that at the center (from +2.16 to $+6.55 \%$ ) for all simulated die angles. The proposed modification of die geometry decreases the difference by up to $93.27 \%$. The R-type die with $\mathrm{R}=2 \mathrm{~mm}$ has less of an impact on the surface and center of radial stress, especially for the die angles $2 \beta=10^{\circ}$ and $14^{\circ}$, and a slightly more considerable variation is observed for $2 \beta=18^{\circ}$. In this case, the superficial radial stress increases, while the stress at the center decreases.

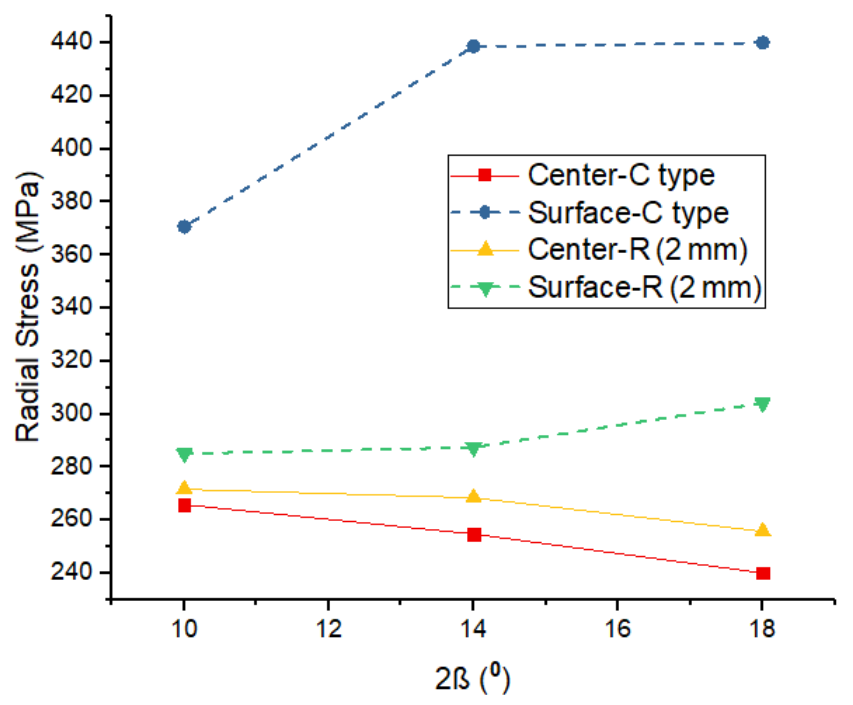

Figure 6. Radial stress in the center and surface of the material for several $2 \beta$.

\section{Conclusions}

The effect of die geometry is a relevant research topic for the metalworking industry, owing to its direct association to productivity and cost-benefit efficiency. The problem is rather complex since it is also affected by various other sensitive factors such as the working conditions, properties of the specimens, etc. Nonetheless, the wire drawing branch, specifically, deserves more attention due to the apparent lack of insightful investigations. The results obtained in the present study may potentially contribute to the ongoing efforts to explore this area. For different die angles as well as bearing zones, investigations are carried out for the wire-drawing process. In particular, by extracting the friction coefficients from the Cu-ETP wire in cold-drawn essays, the numerical simulations are also performed. We present the results for both the superficial and center radial tensions by employing finite element methods. It is found that the reduction of the friction coefficient leads to an increase in radial stress. For a given friction coefficient, the substitution of the C-type die with an R-type one results in a decrease in the superficial radial stress, accompanied by an increase at the center of the material. Moreover, the die angle is found to play a less significant role in the resultant center radial stress, but it significantly affects the superficial radial stress. Last but not least, R-type dies result in smaller superficial radial stress but slightly more significant center radial stress for different die angles. The findings of the present study are meaningful regarding better die geometry designs aimed at reducing the radial stress during and after the wire-drawing process and consequently increasing the production capability of an organization. We plan to continue our study in future works. 
Author Contributions: G.A.S.M. was responsible for the general conceptualization and experimental approach; E.F.d.S. and L.K.K. were responsible for the interpretation of the results; E.S.G. and F.d.A.S. were responsible for simulations with the finite element solver Ansys.

Funding: This research received no external funding.

Conflicts of Interest: The authors declare no conflict of interest.

\section{References}

1. Ajiboye, J.S.; Adeyemi, M.B. Upper bound analysis of die land length in cold extrusion. J. Mater. Process. Technol. 2006, 177, 608-611. [CrossRef]

2. Parghazed, A.; Haghighat, H. Prediction of central bursting defects in rod extrusion process with upper bound analysis method. Trans. Nonferrous Met. Soc. China 2016, 26, 2892-2899. [CrossRef]

3. Suliga, M.; Wartacz, R.; Michalczyk, J. The influence of the angle of the working part of the die on the high speed drawing process of low carbon steel wires. Arch. Metall. Mater. 2017, 62, 483-487. [CrossRef]

4. Stolyarov, A.; Polyakova, M.; Atangulova, G.; Alexandrov, S.; Lang, L. Effect of Frictional Conditions on the Generation of Fine Grain Layers in Drawing of Thin Steel Wires. Metals 2019, 9, 819. [CrossRef]

5. Vannes, A.; Thierry, P. Effects of die characteristic on the strength and residual stresses during wire drawing. J. Mech. Work. Technol. 1981, 5, 251-266. [CrossRef]

6. Castro, A.L.R.; Campos, H.B.; Cetlin, P.R. Influence of die semi-angle on mechanical properties of single and multiple pass drawn copper. J. Mater. Process. Technol. 1996, 60, 179-182. [CrossRef]

7. Kraft, F.F.; Chakkingal, U.; Baker, G.; Wright, R.N. The effects of die angle on the texture and annealing response of ETP copper wire. J. Mater. Process. Technol. 1996, 60, 171-178. [CrossRef]

8. Nakagiri, A.; Yamano, T.; Konaka, M.; Asakawa, M.; Sasaki, W.; Yoshida, K. Behavior of residual stress and drawing stress in conical-type die and circle-type die drawing by FEM simulation and experiment. Wire J. Int. 2001, 34, 72-80.

9. Överstam, H. The influence of bearing geometry on the residual stress state in cold drawn wire, analyzed by the FEM. J. Mater. Process. Technol. 2006, 171, 446-450. [CrossRef]

10. Ikumapayi, O.; Ojolo, S.; Afolalu, A. Experimental and theoretical investigation of tensile stress distribution during aluminum wire drawing. Eur. Sci. J. 2015, 11, 86-102.

11. Teja, C.S.N.; Murty, G.N.; Reddy, P.S. Finite Element Analysis of Wire Drawing Process with different die contours. Int. J. Sci. Eng. Adv. Technol. 2016, 4, 134-143.

12. Tintelecan, M.; Sas-Boca, I.M.; Ilutiu-Varvara, D.A. The influence of the dies geometry on the drawing force for steel wires. Procedia Eng. 2017, 181, 193-199. [CrossRef]

13. Atienza, J.; Elices, M. Influence of residual stresses in the tensile test of cold drawn wires. Mater. Struct. 2003, 36, 548-552. [CrossRef]

14. Martínez-Pérez, M.; Mompean, F.; Ruiz-Hervias, J.; Borlado, C.; Atienza, J.; García-Hernández, M.; Elices, M.; Gil-Sevillano, J.; Peng, R.; Buslaps, T. Residual stress profiling in the ferrite and cementite phases of cold-drawn steel rods by synchrotron X-ray and neutron diffraction. Acta Mater. 2004, 52, 5303-5313. [CrossRef]

15. Atienza, J.M.; Martínez-Pérez, M.L.; Ruiz-Hervias, J.; Mompean, F.; GarcíaHernández, M.; Elices, M. Residual stresses in cold drawn ferritic rods. Scr. Mater. 2005, 52, 305-309. [CrossRef]

16. Martínez-Pérez, M.; Borlado, C.; Mompean, F.; García-Hernández, M.; GilSevillano, J.; Ruiz-Hervias, J.; Atienza, J.; Elices, M.; Peng, R.; Daymond, M. Measurement and modelling of residual stresses in straightened commercial eutectic steel rods. Acta Mater. 2005, 53, 4415-4425. [CrossRef]

17. Coser, T.B.; Souza, T.F.D.; Rocha, A.D.S. Avaliação numérica da influência da geometria do ferramental na geração de tensões residuais durante o processo de trefilação de barras de aço. Rev. Matéria 2015, 20, 819-831. [CrossRef]

18. Kesavulu, P.; Reddy, G.R.; Sreedhar, N. Finite element analysis of concave and convex die contours in wire drawing process. Int. J. Emerg. Technol. Adv. Eng. 2014, 4, 477-480.

19. Wistreich, J.G. Investigation of the Mechanics of Wire Drawing. Proc. Inst. Mech. Eng. 1955, 169, 654-678. [CrossRef]

20. Backofen, W.A. Deformation Processing; Addison-Wesley Pub Co.: Boston, MA, USA, 1972. 
21. Wright, R.N. Practical Use of Mechanical Analysis in Wire Drawing; Wire Technology: Kaukauna, WI, USA, 1976; Volume 9, pp. 57-61.

22. Atkins, A.G.; Caddell, R.M. The incorporation of work hardening and redundant work in rod drawing analyses. Int. J. Mech. Sci. Pergamon Press. 1968, 10, 15-28. [CrossRef]

23. Godfrey, H.J.; Richards, J.F.; Sason, A.S. The benefits of using wiredrawing dies with smaller included angles and long nibs. Wire J. Int. 2000, 6, 102-113.

24. Avitzur, B. Handbook of Metal. Forming; John Wiley and Sons: New York, NY, USA, 1983.

25. Vega, G.; Haddi, A.; Imad, A. Investigation of process parameters effect on the copper-wire drawing. Mater. Des. 2009, 30, 330-3312. [CrossRef]

(C) 2019 by the authors. Licensee MDPI, Basel, Switzerland. This article is an open access article distributed under the terms and conditions of the Creative Commons Attribution (CC BY) license (http://creativecommons.org/licenses/by/4.0/). 